Article

\title{
Encapsulation of $\beta$-Carotene by Emulsion Electrospraying Using Deep Eutectic Solvents
}

\author{
Ahmet Ozan Basar ${ }^{1,2}\left(\mathbb{D}\right.$, Cristina Prieto ${ }^{1, *} \mathbb{C}$, Erwann Durand ${ }^{3,4}$, Pierre Villeneuve ${ }^{3,4}$, \\ Hilal Turkoglu Sasmazel ${ }^{5}$ (D) and Jose Lagaron ${ }^{1, *(D)}$ \\ 1 Novel Materials and Nanotechnology Group, IATA-CSIC, 46980 Valencia, Spain; \\ ozanahmetbasar@gmail.com \\ 2 R\&D Department, Bioinicia S.L., 46980 Valencia, Spain \\ 3 CIRAD, UMR IATE, F-34398 Montpellier, France; erwann.durand@cirad.fr (E.D.); \\ pierre.villeneuve@cirad.fr (P.V.) \\ 4 IATE, Univ Montpellier, CIRAD, INRA, Montpellier SupAgro, F-34398 Montpellier, France \\ 5 Department of Metallurgical and Materials Engineering, Atilim University, 06830 Ankara, Turkey; \\ hilal.sasmazel@atilim.edu.tr \\ * Correspondence: cprieto@iata.csic.es (C.P.); lagaron@iata.csic.es (J.L.); Tel.: +34-963-900-022
}

Academic Editors: Jolanta Sereikaitè and Maria Luisa Ferrer

Received: 3 January 2020; Accepted: 20 February 2020; Published: 22 February 2020

\begin{abstract}
The encapsulation $\beta$-carotene in whey protein concentrate (WPC) capsules through the emulsion electrospraying technique was studied, using deep eutectic solvents (DES) as solvents. These novel solvents are characterized by negligible volatility, a liquid state far below $0{ }^{\circ} \mathrm{C}$, a broad range of polarity, high solubilization power strength for a wide range of compounds, especially poorly water-soluble compounds, high extraction ability, and high stabilization ability for some natural products. Four DES formulations were used, based on mixtures of choline chloride with water, propanediol, glucose, glycerol, or butanediol. $\beta$-Carotene was successfully encapsulated in a solubilized form within WPC capsules; as a DES formulation with choline chloride and butanediol, the formulation produced capsules with the highest carotenoid loading capacity. SEM micrographs demonstrated that round and smooth capsules with sizes around $2 \mu \mathrm{m}$ were obtained. ATR-FTIR results showed the presence of DES in the WPC capsules, which indirectly anticipated the presence of $\beta$-carotene in the WPC capsules. Stability against photo-oxidation studies confirmed the expected presence of the bioactive and revealed that solubilized $\beta$-carotene loaded WPC capsules presented excellent photo-oxidation stability compared with free $\beta$-carotene. The capsules developed here clearly show the significant potential of the combination of DES and electrospraying for the encapsulation and stabilization of highly insoluble bioactive compounds.
\end{abstract}

Keywords: deep eutectic solvents; emulsion electrospraying; encapsulation

\section{Introduction}

The encapsulation of bioactive compounds has emerged as an essential technology in the design of functional foods or active packaging applications [1-3], due to the high sensitivity of these compounds to different physico-chemical factors (temperature, oxygen, humidity, $\mathrm{pH}$, among others), which produce their degradation, loss of nutritional value, and consequently loss of bioavailability [4]. Carotenoids, and concretely $\beta$-carotene, are a good example of this kind of challenging bioactive compounds. In addition to the previous challenge, most of them are insoluble in water, and present low solubility in oils and organic solvents [5-7]. However, the use of this kind of solvents in encapsulation processes could compromise its subsequent application in food or pharmaceutical products due to its toxicity, low solubilization power strength for these compounds, which generates low loading capacities, or could 
not be a healthy option, taking into account the obesity epidemic [8]. The encapsulation of $\beta$-carotene using organic solvents or oils in different biopolymeric matrices was extensively reviewed by Soukoulis and Bohn [9].

A promising alternative is the use of deep eutectic solvents (DES). DES consist of an eutectic mixture of two (or more) components, namely a hydrogen bond acceptor (HBA), such as quaternary ammonium halide salts and metal chloride, and a hydrogen bond donor (HBD), such as alcohols, amides, and carboxylic acids, which are able to self-associate to lead to a liquid temperature of their mixture significantly lower than the pure equivalents $[10,11]$. This new kind of solvents (DES and natural deep eutectic solvents (NADES)) has gained considerable attention due to their unique physicochemical properties, such as negligible volatility, liquid state far below $0{ }^{\circ} \mathrm{C}$, broad range of polarity, high solubilization power strength for a wide range of compounds, especially poorly water-soluble compounds, high extraction ability, and high stabilization ability for some natural products [12,13]. These unique properties together with their relatively low cost, possible biodegradability, and lower toxicity make DES an excellent replacement for traditional organic solvents [14]. Moreover, a kind of DES called natural deep eutectic solvents (NADES) exists, which are solely based on natural substances, such as organic acids, amino acids, and sugars; this also makes them interesting in health-related areas such as pharmaceuticals, food, and cosmetics [15].

Although DES were first reported in the 1990s, the number of applications explored is still scarce [16]. DES have been taken into consideration mainly as extraction media, and as solvents in biocatalytic and enzymatic processes, but some research work related to food and pharmaceutical applications has also been performed. One of the first reported examples related to food or pharmaceutical applications was the use of DES as drug vehicles for transdermal delivery of pharmaceutical compounds [17]. After that, some examples appeared using DES as solvents in conventional encapsulation processes, such as the encapsulation of camptothecin, lidocaine, or folic acid by in situ polymerization [18-21]; the encapsulation of anthocyanins in calcium alginate [22]; and the loading of curcumin into a hydrophilic hydrogel [23]. However, conventional encapsulation processes require the use of high temperatures, toxic reactives, or oxygen permeable polymeric matrices, which could affect the bioactivity of the bioactive compound, or compromise its application in a food or pharmaceutical product.

Electrohydrodynamic spraying or electrospraying is a simple and highly versatile method of liquid atomization by means of electrical forces which allows the production of capsules in the micro, submicro, and nano range [24]. In this process, the liquid flowing out of a capillary nozzle, within a high electrical potential, is forced by the electrostatic forces to be dispersed into fine droplets, which after drying, generate the capsules at room temperature $[25,26]$. This technology is very suitable for the encapsulation of bioactive compounds due to its mild operating conditions. However, the majority of the bioactive ingredients of interest are not readily soluble in water. In those cases, emulsion electrospraying may be a plausible strategy, in which the bioactive is solubilized into the dispersed phase of an oil-in-water $(\mathrm{O} / \mathrm{W})$ emulsion and the encapsulating biopolymer is solubilized in the aqueous phase [27]. In addition, the use of the emulsion allows obtaining particles with narrow size distribution, core-shell structures, and high retention of the bioactive compound [28]. This approach has been employed so far for the encapsulation of a wide number of bioactive compounds within a wide variety of biopolymer matrices [29], including the encapsulation of carotenoids [30,31]. Up to our knowledge, DES have never been applied in the encapsulation of bioactive compounds by electrospraying. The only work related to electrohydrodynamic processing and DES was reported by Mano et al. for the encapsulation of NADES in polymeric fibers by electrospinning [32,33].

The objective of this study is to evaluate the possibility of increasing the stability and loading capacity of $\beta$-carotene in WPC capsules, by using DES as solvents and emulsion electrospraying as the encapsulation technique. $\beta$-carotene is a very well-known model bioactive compound with low solubility, and many works have been published before in the group dealing with the stabilization of $\beta$-carotene [30,34-36]. In this study, we investigated the possibility of generating emulsions with these solvents, using an aqueous solution of WPC as a continuous phase, and DES with or without 
bioactive, as the dispersed phase. The capsules were prepared by emulsion electrospraying and were characterized according to their morphology and loading capacity. The infrared spectrum of the capsules was studied to confirm the presence of DES within the capsules. Finally, a study of stability against photo-oxidation was performed.

\section{Results and Discussion}

\subsection{Characterization of the Emulsion}

First, a physical characterization of the emulsions was performed since it is well-studied that the morphology of electrosprayed materials highly depends on the physical characteristics of the initial polymeric solutions, such as viscosity, surface tension, and electrical conductivity. For instance, the viscosity should be in optimum value in order to form the encapsulation structures from polymer entanglements [37]. The surface tension should be low enough to form a stable Taylor cone that leads a stable electrospraying process [38]. Lastly, the electrical conductivity should not be too high in order to achieve stable electrospraying [39,40].

Initially, different concentrations of WPC were tested in order to obtain a successfully sprayable solution and it was found that a concentration of $30 \%(w / v)$ WPC solution was optimum for the electrospraying process. For a concentration of $20 \%(w / v)$ only drops of material were obtained on the collector. On the other hand, at a concentration of $40 \%(w / v)$ a gelled structured was obtained (results not shown). It was concluded that the optimum concentration for WPC capsule formation was $30 \%$ and, thus, this concentration was used for the rest of the experiments. Thereafter, different emulsion systems were characterized before producing the encapsulation structures. Table 1 shows the prepared O/W emulsions, with solutions of WPC $(30 \% w / v)$ as continuous phase, and DES $(2 \%, 10 \%$ $v / v)$ as the disperse phase. For all cases, 5\% wt. Span 20 surfactant was used.

Table 1. Physical parameters of the studied solutions and emulsions. All samples contain whey protein concentrate (WPC) aqueous solution at a concentration of 30\% w/v and 5\% wt. Span 20. DES, deep eutectic solvents; NADES, natural deep eutectic solvents.

\begin{tabular}{cccc}
\hline Formulations & Viscosity $\mathbf{( c P )}$ & $\begin{array}{c}\text { Surface Tension } \\
(\mathbf{m N} / \mathbf{m})\end{array}$ & $\begin{array}{c}\text { Conductivity } \\
(\mathbf{m S} / \mathbf{c m})\end{array}$ \\
\hline WPC & Solutions & \\
\hline \multicolumn{4}{c}{ Emulsions } \\
\hline WPC + 2\% NADES1 & $101.2 \pm 1.5$ & $31.1 \pm 0.7$ & \\
WPC + 2\% NADES2 & $98.6 \pm 1.4$ & $31.0 \pm 0.1$ \\
WPC + 2\% NADES3 & $98.3 \pm 1.2$ & $32.8 \pm 0.5$ & $6.8 \pm 0.1$ \\
WPC + 2\% DES4 & $100.9 \pm 0.9$ & $35.1 \pm 1.1$ & $6.6 \pm 0.1$ \\
WPC + 10\% NADES1 & $91.2 \pm 1.2$ & $28.9 \pm 0.3$ & $21.1 \pm 1.2$ \\
WPC + 10\% NADES2 & $97.8 \pm 1.7$ & $33.4 \pm 0.6$ & $20.0 \pm 0.9$ \\
WPC + 10\% NADES3 & $99.4 \pm 1.3$ & $30.7 \pm 0.2$ & $20.8 \pm 1.2$ \\
WPC + 10\% DES4 & $95.1 \pm 0.6$ & $33.0 \pm 1.0$ & $19.8 \pm 1.3$ \\
\hline & Emulsions with Bioactive & \\
\hline WPC + 10\% NADES3 + $\beta$-carotene & $95.4 \pm 0.7$ & $31.3 \pm 0.9$ & $16.0 \pm 0.7$ \\
WPC + 10\% DES4 + $\beta$-carotene & $93.0 \pm 1.3$ & $32.6 \pm 0.4$ & $15.7 \pm 0.3$ \\
\hline
\end{tabular}

Results in Table 1 show that the average viscosity of the WPC solution was increased with the incorporation of DES from $61.8 \mathrm{cP}$ to $101.2 \mathrm{cP}$. However, no significant differences were observed when increasing the percentage of DES from $2 \%$ to $10 \%$ in the emulsions. The surface tension of all the systems was low enough for electrospraying, as the values did not exceed the limit of $50 \mathrm{mN} / \mathrm{m}$ which was suggested previously as the limit for electrospraying [41], thanks to the use of the surfactant. 
The electrical conductivity values increased with the addition of DES. Most particularly, the conductivity values increased approximately $212 \%$ due to the increase in the DES concentration from $2 \%$ to $10 \%$. Furthermore, the addition of antioxidant, $\beta$-carotene, decreased the conductivity $21.8 \%$ on average, due to the well-known low polarity of the bioactive.

\subsection{Morphology}

SEM images shown in Figure 1 demonstrate that round, smooth WPC capsules are obtained through electrospraying from WPC $+10 \%$ DES4 system. As seen from the figure, $\beta$-carotene-containing WPC capsules (Figure 1c,d) exhibited similar morphology with the non- $\beta$-carotene-containing WPC capsules (Figure 1a,b). Furthermore, these particles were similar in size to those obtained in previous work for WPC/glycerol systems [30]. Mean capsule diameters were $2.56 \mu \mathrm{m}$ (Figure 1c,d) and $2.51 \mu \mathrm{m}$ (Figure 1a,b) for the neat WPC and $\beta$-carotene-containing WPC capsules, respectively. The here-observed capsule diameters were relatively high despite the low surface tension values (Table 1), which are normally considered as a factor to influence the morphology of electrospun systems [30]. Therefore, other factors like solution properties (e.g., conductivity, viscosity) and processing parameters, including polymer degradation, may be playing a major role in determining capsule size [42].
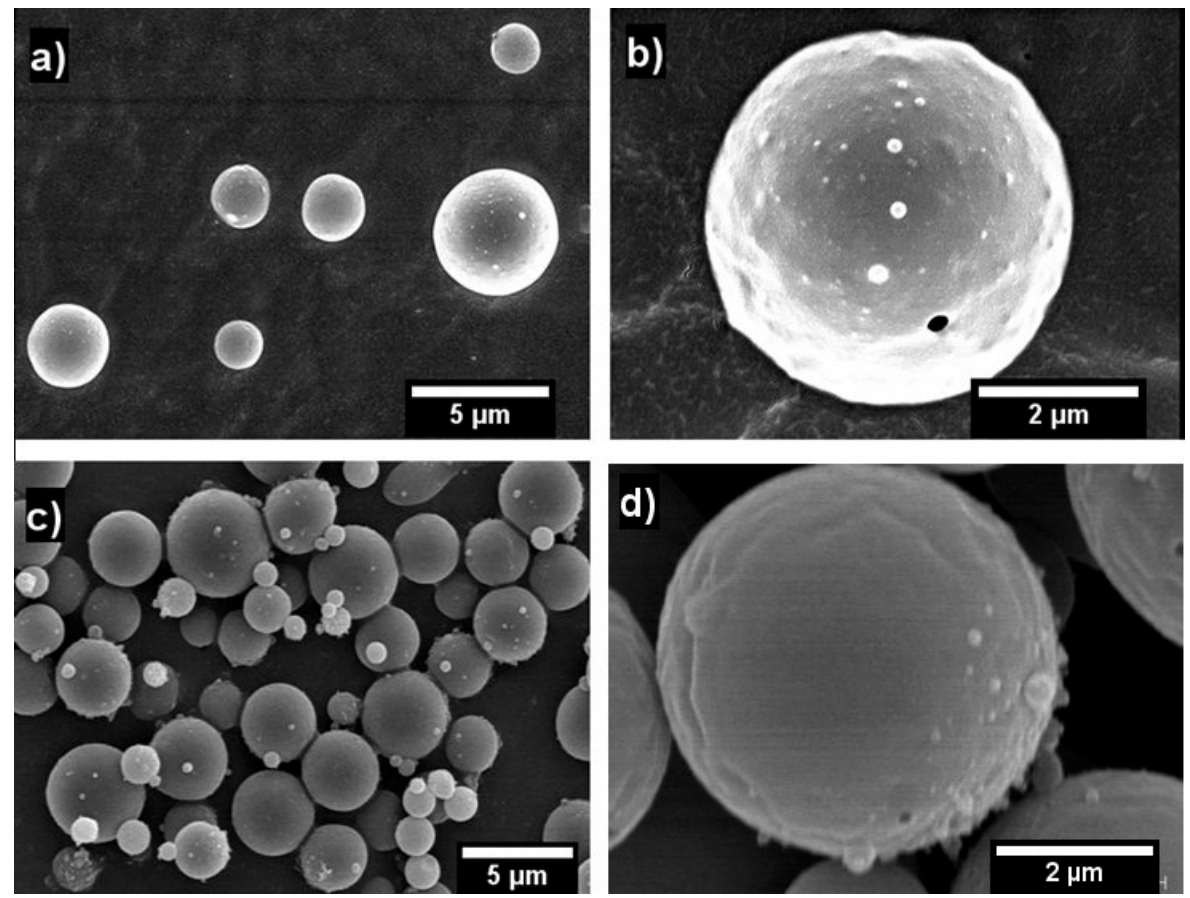

Figure 1. Scanning electron microscopy (SEM) images of the electrosprayed capsules of: (a) $30 \%$ WPC $+10 \%$ DES4 with scale marker of $5 \mu \mathrm{m}$; (b) $30 \%$ WPC + 10\% DES4 with scale marker of $2 \mu \mathrm{m}$; (c) $30 \%$ $\mathrm{WPC}+10 \% \mathrm{DES} 4+\beta$-carotene with scale marker of $5 \mu \mathrm{m} ;(\mathbf{d}) 30 \% \mathrm{WPC}+10 \% \mathrm{DES} 4+\beta$-carotene with scale marker of $2 \mu \mathrm{m}$.

Since DES and surfactant do not show volatility and the surface morphology of the particles exhibit some roughness with spherical features, it is expected that the $\beta$-carotene dissolved in DES will be homogeneously distributed in nanovesicles within the microparticles, as seen in previous works by the same authors $[43,44]$. The fact that the DES and surfactant remain inside the capsule should not bring a problem in commercial formulations, since all the components are currently being used as additives in foods, and in addition, they could promote absorption at the gastrointestinal tract [45]. 


\subsection{Loading Capacity}

It is well-known that $\beta$-carotene is a bioactive compound with a low bioavailability due to its accused lipophilicity; indeed, only $20 \%$ of the $\beta$-carotene consumed is absorbed in the gastrointestinal tract [9], as the recommended daily dose of $\beta$-carotene for an adult is between 1.6 and $9.6 \mathrm{mg}$ [46]. In order to estimate the daily dose intake, it is essential to calculate the loading capacity of the capsules.

The loading capacity of the capsules produced with a concentration of $2 \%$ NADES/DES was relatively low $\left(6.67 \times 10^{-3} \% \max , 0.0667 \times 10^{-3} \% \mathrm{~min}\right)$. The highest $\beta$-carotene loading capacity was calculated for the WPC emulsion with $10 \%$ DES4 $\left(37 \times 10^{-3} \%\right)$ since the initial concentration of $\beta$-carotene in DES4 was the highest $(1000 \mu \mathrm{g} / \mathrm{mL})$. This loading capacity entails that a consumption of $4 \mathrm{~g}$ of capsules is required to obtain the recommended intake. Previous studies, such as the work of Rodrigues et al., reported very little loading capacities, meaning that up to $100 \mathrm{~g}$ of capsules may be required to get the recommended daily intake [31]. In a previous study carried out in a lab by López-Rubio et al. [30], a loading capacity of $79.3 \times 10^{-3} \%$ was obtained via the encapsulation in WPC of a suspension of $\beta$-carotene particles in glycerol (results shown in Table 2). The obtained loading capacity by López-Rubio et al. [30] would then require a potential consumption of $2 \mathrm{~g}$ of capsules. However, since bioavailability is known to be significantly better in solution [47], rather than in particles suspension, the use of DES can thus help improve the bioavailability of $\beta$-carotene. Hence, this emulsion was used for further experiments.

Table 2. Loading capacity of $\beta$-carotene-loaded WPC capsules.

\begin{tabular}{cc}
\hline Formulation & Loading Capacity $\mathbf{1 0}^{\mathbf{3}} \mathbf{( \% )}$ \\
\hline WPC + 2\% NADES1 & $1.6 \pm 0.2$ \\
WPC + 2\% NADES2 & $0.1 \pm 0.0$ \\
WPC + 2\% NADES3 & $0.6 \pm 0.0$ \\
WPC + 2\% DES4 & $6.2 \pm 0.3$ \\
WPC + 10\% NADES3 & $3.1 \pm 0.1$ \\
WPC + 10\% DES4 & $37.0 \pm 2.4$ \\
López-Rubio et al. [30] & $79.3 *$ \\
\hline
\end{tabular}

* It was estimated theoretically from the formulation.

\subsection{Infrared Spectroscopy}

ATR-FTIR spectroscopy was performed to analyze the obtained capsules and verify the presence of the DES containing $\beta$-carotene in the capsules produced. Figure 2 shows the FTIR spectra of pure WPC, ChCl:butanediol (DES4), pure $\beta$-carotene crystals, and WPC $+10 \%$ DES4 $+\beta$-carotene capsules. The ATR-FTIR spectrum of the $\beta$-carotene-loaded encapsulate shows contributions from both the protein wall material and the DES4 solvent containing $\beta$-carotene. The characteristic bands of proteins (i.e., Amide I $(\vee \mathrm{C}=\mathrm{O}, \vee \mathrm{C}-\mathrm{N})$ at $1650 \mathrm{~cm}^{-1}$ and Amide II $(\delta \mathrm{N}-\mathrm{H}, \vee \mathrm{C}-\mathrm{N})$ at $\left.1550 \mathrm{~cm}^{-1}\right)$ were clearly discerned in the spectrum of the $\beta$-carotene-loaded WPC encapsulate [48]. The $\beta$-carotene-loaded encapsulate also showed a considerable relative increase in the absorbance of the bands between 2800 and $3600 \mathrm{~cm}^{-1}$ with respect to the pure protein, assigned to the contribution of the DES4 solvent. Thus, the bands between $3000-3600 \mathrm{~cm}^{-1}$ are attributed to DES solvent $\mathrm{N}-\mathrm{H}$ and $\mathrm{O}-\mathrm{H}$ groups [49], responsible for forming hydrogen bonds with carbonyl groups of the peptides in the proteins [50]; and the bands between $2800-3000 \mathrm{~cm}^{-1}$ are assigned to DES solvent $\mathrm{C}-\mathrm{H}$ stretching vibrations of carbonyl groups [51]. In addition, the ATR-FTIR spectrum of the encapsulate containing $\beta$-carotene shows a new peak at $1080 \mathrm{~cm}^{-1}$, which corresponds to the $\mathrm{C}-\mathrm{O}$ stretching peaks of the primary alcohol in $\mathrm{ChCl}$ :butanediol components in DES4 [52]. As seen from Figure 2, no characteristic peaks of $\beta$-carotene were detected in the ATR-FTIR spectrum of the encapsulate containing $\beta$-carotene. This is most likely due to the low concentration of $\beta$-carotene in the capsules, whose contribution would be masked by the intense peaks of the WPC. However, the presence of the DES bands suggests indirectly the presence of $\beta$-carotene, 
since the carotenoid is dissolved in the solvent. In any case, the presence of $\beta$-carotene in the capsules was confirmed by UV/Vis spectrophotometry as shown in the following section.

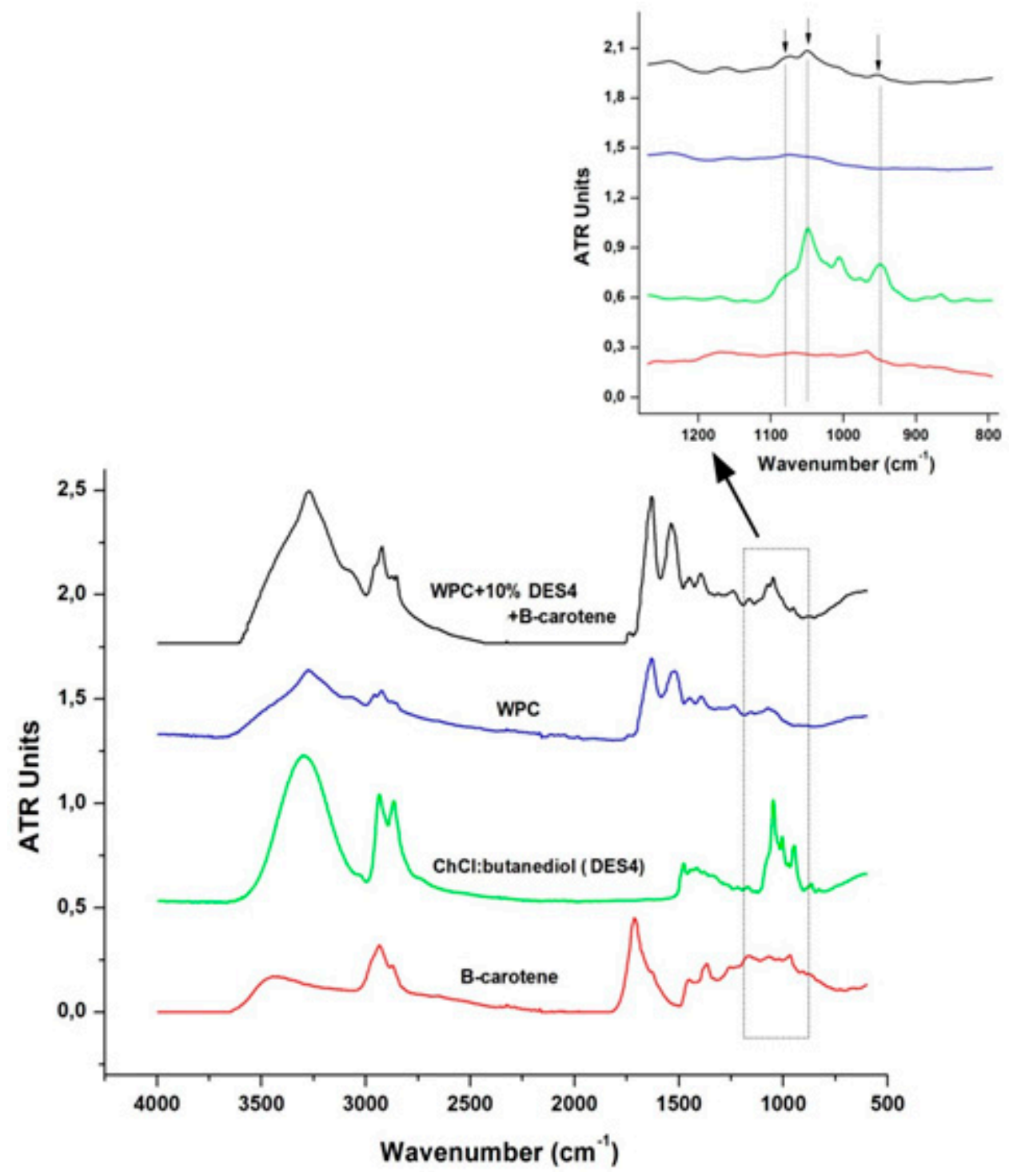

Figure 2. ATR-FTIR spectra of electrosprayed capsules. From bottom to top: pure $\beta$-carotene crystals, ChCl:butanediol (DES4), pure WPC, and WPC $+10 \%$ DES4 $+\beta$-carotene capsules. The arrows point to the spectral band related to the presence of ChCl:butanediol (DES4).

\subsection{Stability of the WPC Capsules Containing $\beta$-Carotene Against Photooxidation}

The confirmation of the presence, and subsequent quantification, of $\beta$-carotene in the capsules was done by resolubilization of these for the stability study after UV exposure. Thus, a comparison of the photostability between $\beta$-carotene in hexane and $\beta$-carotene microencapsulated in WPC was carried out and can be seen in Figure 3. At the same time, we checked that the efficiency of the encapsulation process was $100 \%$, since all $\beta$-carotene in the solution was found trapped in the capsules. $\beta$-carotene is a highly light-sensitive molecule due to the double bonds in the molecule [35] and its photoisomerization is often considered as being able to occur in solution, hexane in this case, but not very readily in dry particles [53]. As observed in the figure, the $\beta$-carotene loaded WPC capsules showed very good photo-oxidation stability. After $180 \mathrm{~min}(3 \mathrm{~h})$ of light exposure, complete degradation of the free $\beta$-carotene in the hexane solution was measured, whereas $72 \%$ of the encapsulated $\beta$-carotene remained stable in the same time interval. 


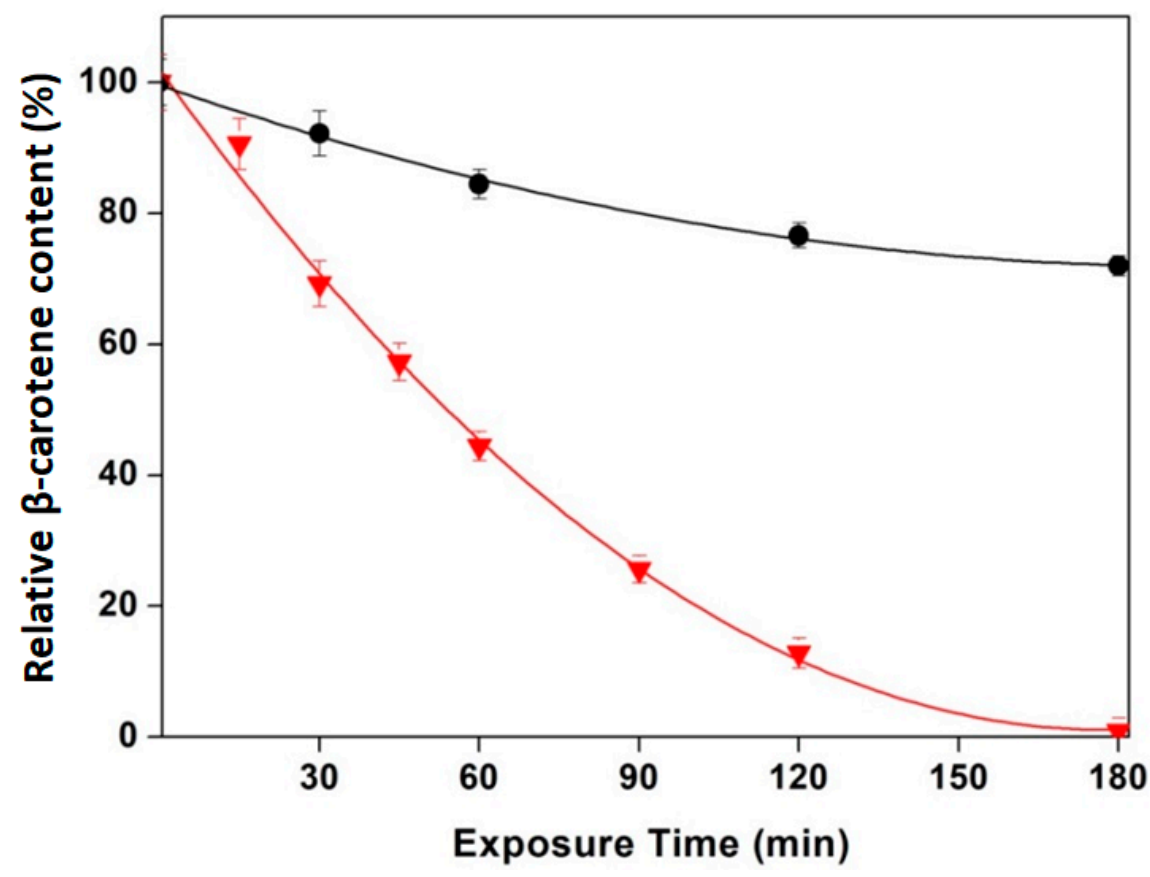

Figure 3. Relative photo-oxidation vs. UV/Vis exposure time in the $\beta$-carotene concentration measure by UV/Vis spectroscopy at $448 \mathrm{~nm}$ of $(\bullet)$ as WPC $+10 \%$ DES4 $+\beta$-carotene capsules, $(\mathbf{v})$ free $\beta$-carotene.

\section{Materials and Methods}

\subsection{Materials}

Whey protein concentrate (WPC) was purchased from Davisco Foods (Le Sueur, MN, USA) and was used without further purification. The composition per $100 \mathrm{~g}$ of product consisted of $\sim 80 \mathrm{~g}$ of protein, $\sim 9 \mathrm{~g}$ of lactose, and $\sim 8 \mathrm{~g}$ of lipids, the rest being water and minerals. The surfactant (Span20), synthetic $\beta$-carotene $\geq 93 \%, 1,4$ butanediol 99\% (ReagentPlus ${ }^{\circledR}$ ), choline chloride $\geq 98 \%(\mathrm{ChCl})$, glycerol $\geq 99 \%$, and glucose were purchased from Sigma-Aldrich (St. Louis, MO, USA). Distilled water was used throughout the study. N-hexane (98\% purity) was purchased from Aklar Kimya (Ankara, Turkey). Ultra-Vitalux (300 W) lamp was purchased from OSRAM (Munich, Germany).

\subsection{Preparation of NADES and $\beta$-Carotene Solutions}

Four different deep eutectic solvents, NADES1 (ChCl:propanediol:water), NADES2 (ChCl:Glucose:water), NADES3 (ChCl:Glycerol), and DES4 (ChCl:butanediol), were prepared by weighting the components in proper mole ratios, respectively 1:1:1, 5:2:5, 1:2, and 1:2. The mixtures were heated under stirring at $50{ }^{\circ} \mathrm{C}$ until a clear liquid was obtained. The mixtures remained in the liquid state after cooling to room temperature. Then, solutions of $\beta$-carotene in NADES1 $(250 \mu \mathrm{g} / \mathrm{mL})$, NADES2 $(10 \mu \mathrm{g} / \mathrm{mL})$, NADES3 $(100 \mu \mathrm{g} / \mathrm{mL})$, and DES4 $(1000 \mu \mathrm{g} / \mathrm{mL})$ were prepared, corresponding to the highest concentration of $\beta$-carotene that can be attained in those mixtures at room temperature. It should be noted that $\beta$-carotene is insoluble in ethanol, glycerol, and propylene glycol; slightly soluble in boiling organic solvents such as ether $(0.05 \%)$, benzene $(0.2 \%)$, carbon disulfide $(1 \%)$, and methylene chloride $(0.5 \%)$; its solubility in edible oils is of $0.08 \%$ at room temperature, $0.2 \%$ at $60{ }^{\circ} \mathrm{C}$, and $0.8 \%$ at $100{ }^{\circ} \mathrm{C}$ [54]. The calculated solubility of $\beta$-carotene in DES4 is of ca. $0.08 \%$, similar to that of oil at room temperature.

\subsection{Preparation of WPC Solutions}

WPC solutions were prepared by dissolving a precise amount of the material in distilled water through gentle stirring at room temperature in order to achieve three different WPC concentrations 
of $20 \%, 30 \%$, and $40 \%(w / v)$. These solutions were used first to prepare the single WPC capsules. For all cases, $5 \mathrm{wt}$ \% of Span 20 surfactant was used to facilitate the electrospraying process. In case of emulsions, $\beta$-carotene solubilized in the four different DES solutions was added to the aqueous WPC solutions to attain a final $2 \%$ and $10 \%(v / v)$ concentrations. The resultant mixture was homogenized using a TX4 Digital Vortex Mixer from Velp (Usmate, Italy) to generate an emulsion.

\subsection{Electrospraying Process}

The electrospraying apparatus used was a Fluidnatek LE-50 Capsultek ${ }^{\circledR}$ tool from Bioinicia S.L. (Valencia, Spain) in the lab mode configuration, with a single needle injector placed horizontally towards a grounded flat collector. The equipment has a variable high-voltage 0-30 kV power supply, and a $5 \mathrm{~mL}$ plastic syringe was used as a reservoir for the solution. The distance between the needle and the collector was set at $15 \mathrm{~cm}$. The capsules were obtained using a voltage range of $17-23 \mathrm{kV}$ and a flow rate range of $50-100 \mu \mathrm{L} / \mathrm{h}$. The operation parameters were optimized for each formulation to get a stable cone of Taylor, which ensures stable processing. The particles were collected dry and no further drying procedure was applied. The efficiency of the process, in terms of the bioactive present in the collector vs. that in the starting solution, was found to be of $100 \%$ for the lab scale system used.

\subsection{Characterization}

\subsubsection{Characterization of the Solutions and Emulsions}

Emulsions and solutions were characterized in terms of surface tension, viscosity, and conductivity. The surface tension was measured using the Wilhemy plate method in an EasyDyne K20 tensiometer (Krüss GmbH, Hamburg, Germany). The viscosity was measured using Visco Basic Plus (Fungilab, Barcelona, Spain). The conductivity measurements were carried out using a HI98192 conductivity probe (Hanna Instruments, Gothenburg, Sweden). All the measurements were performed at room temperature.

\subsubsection{Morphological Characterization}

The morphology of the capsules was examined by scanning electron microscopy (SEM). The SEM micrographs were taken using a Hitachi S-4800 electron microscope (Tokyo, Japan) at an accelerating voltage of $10 \mathrm{kV}$ and working distance of $8 \mathrm{~mm}$. A few milligrams of the collected powder were deposited over a double side carbon strip prior to sputtering with a gold-palladium mixture for 3 min under vacuum. The average capsule diameter was determined via ImageJ Launcher software program from the SEM micrographs in their original magnification.

\subsubsection{Loading Capacity of Whey Protein Concentrate (WPC) Capsules}

Weight percent loading capacity (LC) was calculated on the basis of the mass of $\beta$-carotene over the mass of WPC capsules containing $\beta$-carotene, in duplicate. It can be represented as:

$$
L C(\%)=\frac{\text { Mass of } \beta-\text { carotene }}{\text { Mass of } \beta-\text { carotene }+ \text { Mass of WPC }+ \text { Mass of Surfactant }+ \text { Mass of DES }} \cdot 100 \%
$$

\subsubsection{Infrared Spectroscopy}

Attenuated total reflectance infrared spectroscopy (ATR-FTIR) experiments were performed using a Bruker FTIR Tensor 37 equipment (Rheinstetten, Germany). Approximately $50 \mathrm{mg}$ of capsules were placed on top of the diamond crystal and good contact was assured by using the ATR Sampling Accessory low temperature Golden Gate (Specac Ltd., Orpington, UK). All the spectra were obtained within the wavenumber range of $4000-600 \mathrm{~cm}^{-1}$ by averaging 10 scans at $4 \mathrm{~cm}^{-1}$ resolution. Measurements were performed in triplicate. Analysis of spectral data was carried out using the OPUS 4.0 data collection software program (Bruker, Ettlingen, Germany). 


\subsubsection{Stability of the WPC Capsules Containing $\beta$-Carotene Against Photooxidation}

Stability against photo-oxidation of the $\beta$-carotene-containing WPC capsules was studied by placing the various samples under UV light at room temperature. For this purpose, the antioxidant degradation rate was compared with that of $\beta$-carotene encapsulated in WPC capsules and $\beta$-carotene crystals dissolved in hexane which were placed under an Osram Ultra-Vitalux (300 W) lamp in order to accelerate the oxidation of $\beta$-carotene over $3 \mathrm{~h}$. This lamp produces an intense mix of radiation very similar to that of natural sunlight. This blend of radiation is generated by a quartz discharge tube and a tungsten filament. The bulb is made of special glass which allows only that part of the output that is contained in natural sunlight to pass through. The distance between the lamp and the samples was $20 \mathrm{~cm}$. Samples were collected over periods of illumination times and the intact $\beta$-carotene concentration was determined using T80+ UV/Vis Spectrometer (PG Instruments Ltd., Lutterworth, UK) at $448 \mathrm{~nm}$. The $\beta$-carotene concentration of the control samples containing $\beta$-carotene crystals dissolved in n-hexane was determined directly by spectrophotometry. For the solutions of $\beta$-carotene-loaded WPC capsules, distilled water was added to disrupt the WPC capsules before hexane was added to extract the $\beta$-carotene. This two-phase system was generated by the ratio of 1:5 water:hexane composition. This mixture was ultrasonicated for $60 \mathrm{~min} 20^{\circ} \mathrm{C}$ with JY92-IIN Ultrasonic Homogenizer (Hinotek, Ningbo, China) and then centrifuged at $9000 \mathrm{rpm}$ for $3 \mathrm{~min}$. The organic (upper) phase was separated, and the $\beta$-carotene concentration was determined by spectrophotometry.

\section{Conclusions}

In this paper, the encapsulation of a bioactive compound by electrospraying using DES as a solvent was screened for the first time. DES are presented as a green alternative for the encapsulation of challenging bioactive compounds due to their low solvation capacity in conventional solvents via the electrospraying encapsulation process. Four different DES formulations were tested, based on mixtures of choline chloride with propanediol, water, glucose, glycerol, and butanediol. First, the formulation of stable O/W emulsions was studied, using WPC aqueous solutions as continuous phase and $\beta$-carotene in DES solutions as dispersed phase. Ratios dispersed phase:continuous phase of 2:98 provided stable emulsions with DES formulations containing choline chloride, water, propanediol, glucose, or glycerol. However, DES containing choline chloride and butanediol generated stable emulsions at ratios 10:90, and in this solvent the highest amount of $\beta$-carotene was solubilized. With this DES formulation, spherical and smooth $\beta$-carotene in a solubilized form loaded WPC capsules with sizes around $2 \mu \mathrm{m}$ were obtained. Loading capacity in these capsules was the highest for the formulations studied, achieving values in the same order of magnitude of the loading capacity obtained previously using suspensions of $\beta$-carotene particles in glycerol. The presence of DES inside the capsules was demonstrated by ATR-FTIR spectroscopy. The accelerated oxidative stability test performed confirmed the protective role of the biopolymer wall. While the free $\beta$-carotene oxidized completely within $180 \mathrm{~min}$ under UV light, the $\beta$-carotene loaded in the WPC capsules only oxidized around $20 \%$. Nevertheless, it would be interesting to explore other NADES formulations and encapsulants that may offer a greater $\beta$-carotene solubilization capacity and thus further enhance the loading capacity. The promising results obtained in this work with the combination of DES and the electrospraying processing technique, make the present study of fundamental value in the emerging area of bioactives encapsulation.

Author Contributions: Conceptualization was devised by E.D., P.V., H.T.S., and J.L.; methodology, validation, and formal analysis were performed by A.O.B., C.P., and J.L.; investigation, resources, data curation, writing-original draft preparation, writing-review and editing were carried out by A.O.B., C.P., H.T.S., and J.L.; supervision: J.M.L. and C.P.; project administration and funding acquisition: H.T.S. and J.L. All authors have read and agreed to the published version of the manuscript.

Funding: This research was funded by the COST Action FP1405 (STSM reference number 41084), the MICIU project (RTI-2018-097249-B-C21), the Valencian Innovation Agency (AVI) BIOENCAP project (reference number INNCAD00-18-31), the H2020 EU FODIAC project (reference number 778388), and the H2020 EU projects CAPSULTEK (reference number 873827). 
Conflicts of Interest: The authors declare no conflicts of interest.

\section{References}

1. Augustin, M.A. The role of microencapsulation in the development of functional dairy foods. Aust. J. Dairy Technol. IDF World Symp. Dairy Prod. Human Health 2003, 58, 5.

2. Cha, D.S.; Chinnan, M.s. Emerging Role of Nisin in Food and Packaging Systems. Food Sci. Biotecnol. 2003, 12, 206-212.

3. Lopez-Rubio, A.; Gavara, R.; Lagaron, J.M. Bioactive packaging: turning foods into healthier foods through biomaterials. Trends Food Sci. Technol. 2006, 17, 567-575. [CrossRef]

4. Sobel, R.; Versic, R.; Gaonkar, A.G. Chapter 1 - Introduction to Microencapsulation and Controlled Delivery in Foods. In Microencapsulation in the Food Industry; Gaonkar, A.G., Vasisht, N., Khare, A.R., Sobel, R., Eds.; Academic Press: Cambridge, MA, USA, 2014; pp. 3-12. [CrossRef]

5. de Paz, E.; Martín, Á.; Bartolomé, A.; Largo, M.; Cocero, M.J. Development of water-soluble $\beta$-carotene formulations by high-temperature, high-pressure emulsification and antisolvent precipitation. Food Hydrocoll. 2014, 37, 14-24. [CrossRef]

6. Liu, W.; Wang, J.; McClements, D.J.; Zou, L. Encapsulation of $\beta$-carotene-loaded oil droplets in caseinate/alginate microparticles: Enhancement of carotenoid stability and bioaccessibility. J. Funct. Foods 2018, 40, 527-535. [CrossRef]

7. Soukoulis, C.; Tsevdou, M.; Andre, C.M.; Cambier, S.; Yonekura, L.; Taoukis, P.S.; Hoffmann, L. Modulation of chemical stability and in vitro bioaccessibility of beta-carotene loaded in kappa-carrageenan oil-in-gel emulsions. Food Chem. 2017, 220, 208-218. [CrossRef]

8. Mitchell, N.S.; Catenacci, V.A.; Wyatt, H.R.; Hill, J.O. Obesity: overview of an epidemic. Psychiatr. Clin. North Am. 2011, 34, 717-732. [CrossRef]

9. Soukoulis, C.; Bohn, T. A comprehensive overview on the micro- and nano-technological encapsulation advances for enhancing the chemical stability and bioavailability of carotenoids. Crit. Rev. Food Sci. Nutr. 2018, 58, 1-36. [CrossRef]

10. Abbott, A.P.; Boothby, D.; Capper, G.; Davies, D.L.; Rasheed, R.K. Deep Eutectic Solvents Formed between Choline Chloride and Carboxylic Acids: Versatile Alternatives to Ionic Liquids. J. Am. Chem. Soc. 2004, 126, 9142-9147. [CrossRef]

11. Abbott, A.P.; Capper, G.; Davies, D.L.; Rasheed, R.K.; Tambyrajah, V. Novel solvent properties of choline chloride/urea mixtures. Chem. Commun. 2003, 10, 70-71. [CrossRef]

12. Othman, Z.S.; Hassan, N.H.; Zubairi, S.I. Alcohol based-deep eutectic solvent (DES) as an alternative green additive to increase rotenone yield. AIP Conf. Proc. 2015, 1678, 050004. [CrossRef]

13. Dai, Y.; Witkamp, G.-J.; Verpoorte, R.; Choi, Y.H. Tailoring properties of natural deep eutectic solvents with water to facilitate their applications. Food Chem. 2015, 187, 14-19. [CrossRef] [PubMed]

14. Carson, P.; Mumford, C. 6-Flammable chemicals. In Hazardous Chemicals Handbook (Second edition); Carson, P., Mumford, C., Eds.; Butterworth-Heinemann: Oxford, UK, 2002; pp. 178-227. [CrossRef]

15. Paiva, A.; Craveiro, R.; Aroso, I.; Martins, M.; Reis, R.L.; Duarte, A.R.C. Natural Deep Eutectic Solvents-Solvents for the 21st Century. ACS Sustain. Chem. Eng. 2014, 2, 1063-1071. [CrossRef]

16. Martins, M.; Aroso, I.M.; Reis, R.L.; Duarte, A.R.C.; Craveiro, R.; Paiva, A. Enhanced performance of supercritical fluid foaming of natural-based polymers by deep eutectic solvents. AIChE J. 2014, 60, 3701-3706. [CrossRef]

17. Stott, P.W.; Williams, A.C.; Barry, B.W. Transdermal delivery from eutectic systems: enhanced permeation of a model drug, ibuprofen. J. Control. Release 1998, 50, 297-308. [CrossRef]

18. Sánchez-Leija, R.J.; Pojman, J.A.; Luna-Bárcenas, G.; Mota-Morales, J.D. Controlled release of lidocaine hydrochloride from polymerized drug-based deep-eutectic solvents. J. Mater. Chem. B 2014, 2, 7495-7501. [CrossRef]

19. Pradeepkumar, P.; Elgorban, A.M.; Bahkali, A.H.; Rajan, M. Natural solvent-assisted synthesis of amphiphilic co-polymeric nanomicelles for prolonged release of camptothecin delivery. New J. Chem. 2018, 42, 10366-10375. [CrossRef] 
20. Pradeepkumar, P.; Sangeetha, R.; Gunaseelan, S.; Varalakshmi, P.; Chuturgoon, A.A.; Rajan, M. Folic Acid Conjugated Polyglutamic Acid Drug Vehicle Synthesis through Deep Eutectic Solvent for Targeted Release of Paclitaxel. ChemistrySelect 2019, 4, 10225-10235. [CrossRef]

21. Pradeepkumar, P.; Subbiah, A.; Rajan, M. Synthesis of bio-degradable poly(2-hydroxyethyl methacrylate) using natural deep eutectic solvents for sustainable cancer drug delivery. SN Appl. Sci. 2019, 1, 568. [CrossRef]

22. Zeng, Y.-J.; Xu, P.; Yang, H.-R.; Zong, M.-H.; Lou, W.-Y. Purification of anthocyanins from saskatoon berries and their microencapsulation in deep eutectic solvents. LWT 2018, 95, 316-325. [CrossRef]

23. Liu, Y.; Zhang, Y.; Chen, S.-N.; Friesen, J.B.; Nikolić, D.; Choules, M.P.; McAlpine, J.B.; Lankin, D.C.; Gemeinhart, R.A.; Pauli, G.F. The influence of natural deep eutectic solvents on bioactive natural products: studying interactions between a hydrogel model and Schisandra chinensis metabolites. Fitoterapia 2018, 127, 212-219. [CrossRef] [PubMed]

24. Jaworek, A.; Sobczyk, A.T. Electrospraying route to nanotechnology: An overview. J. Electrost. 2008, 66, 197-219. [CrossRef]

25. López-Rubio, A.; Sanchez, E.; Sanz, Y.; Lagaron, J.M. Encapsulation of Living Bifidobacteria in Ultrathin PVOH Electrospun Fibers. Biomacromolecules 2009, 10, 2823-2829. [CrossRef] [PubMed]

26. Torres-Giner, S.; Martinez-Abad, A.; Ocio, M.J.; Lagaron, J.M. Stabilization of a Nutraceutical Omega-3 Fatty Acid by Encapsulation in Ultrathin Electrosprayed Zein Prolamine. J. Food Sci. 2010, 75, N69-N79. [CrossRef]

27. Gómez-Mascaraque, L.; Ambrosio-Martín, J.; Fabra, M.; Perez-Masia, R.; López-Rubio, A. Novel Nanoencapsulation Structures for Functional Foods and Nutraceutical Applications. In Nanotechnology in Nutraceuticals: Production to Consumption; Sen, S., Pathak, Y., Eds.; CRC Press: Boca Ratón, FL, USA, 2016; pp. 373-395.

28. Pinto Reis, C.; Neufeld, R.J.; Ribeiro, A.J.; Veiga, F. Nanoencapsulation, I. Methods for preparation of drug-loaded polymeric nanoparticles. Nanomed. Nanotechnol. Biol. Med. 2006, 2, 8-21. [CrossRef]

29. Echegoyen, Y.; Fabra, M.J.; Castro-Mayorga, J.L.; Cherpinski, A.; Lagaron, J.M. High throughput electro-hydrodynamic processing in food encapsulation and food packaging applications: Viewpoint. Trends Food Sci. Technol. 2017, 60, 71-79. [CrossRef]

30. López-Rubio, A.; Lagaron, J.M. Whey protein capsules obtained through electrospraying for the encapsulation of bioactives. Innov. Food Sci. Emerg. Technol. 2012, 13, 200-206. [CrossRef]

31. Rodrigues, R.M.; Ramos, P.E.; Cerqueira, M.F.; Teixeira, J.A.; Vicente, A.A.; Pastrana, L.M.; Pereira, R.N.; Cerqueira, M.A. Electrosprayed whey protein-based nanocapsules for $\beta$-carotene encapsulation. Food Chem. 2020, 314, 126157. [CrossRef]

32. Mano, F.; Aroso, I.M.; Barreiros, S.; Borges, J.P.; Reis, R.L.; Duarte, A.R.C.; Paiva, A. Production of Poly(vinyl alcohol) (PVA) Fibers with Encapsulated Natural Deep Eutectic Solvent (NADES) Using Electrospinning. ACS Sustain. Chem. Eng. 2015, 3, 2504-2509. [CrossRef]

33. Mano, F.; Martins, M.; Sá-Nogueira, I.; Barreiros, S.; Borges, J.P.; Reis, R.L.; Duarte, A.R.C.; Paiva, A. Production of Electrospun Fast-Dissolving Drug Delivery Systems with Therapeutic Eutectic Systems Encapsulated in Gelatin. AAPS PharmSciTech 2017, 18, 2579-2585. [CrossRef]

34. de Freitas Zômpero, R.H.; López-Rubio, A.; de Pinho, S.C.; Lagaron, J.M.; de la Torre, L.G. Hybrid encapsulation structures based on $\beta$-carotene-loaded nanoliposomes within electrospun fibers. Colloids Surf. $B$ Biointerfaces 2015, 134, 475-482. [CrossRef] [PubMed]

35. Ramos-Hernández, J.A.; Ragazzo-Sánchez, J.A.; Calderón-Santoyo, M.; Ortiz-Basurto, R.I.; Prieto, C.; Lagaron, J.M. Use of Electrosprayed Agave Fructans as Nanoencapsulating Hydrocolloids for Bioactives. Nanomaterials (Basel) 2018, 8, 868. [CrossRef] [PubMed]

36. Cruz-Salas, C.N.; Prieto, C.; Calderón-Santoyo, M.; Lagarón, J.M.; Ragazzo-Sánchez, J.A. Micro- and Nanostructures of Agave Fructans to Stabilize Compounds of High Biological Value via Electrohydrodynamic Processing. Nanomaterials 2019, 9, 1659. [CrossRef] [PubMed]

37. Bock, N.; Dargaville, T.R.; Woodruff, M.A. Electrospraying of polymers with therapeutic molecules: State of the art. Prog. Polym. Sci. 2012, 37, 1510-1551. [CrossRef]

38. Ding, L.; Lee, T.; Wang, C.-H. Fabrication of monodispersed Taxol-loaded particles using electrohydrodynamic atomization. J. Control. Release 2005, 102, 395-413. [CrossRef] 
39. Shenoy, S.L.; Bates, W.D.; Frisch, H.L.; Wnek, G.E. Role of chain entanglements on fiber formation during electrospinning of polymer solutions: good solvent, non-specific polymer-polymer interaction limit. Polymer 2005, 46, 3372-3384. [CrossRef]

40. Torres-Giner, S.; Busolo, M.; Cherpinski, A.; Lagaron, J.M. CHAPTER 10 Electrospinning in the Packaging Industry. In Electrospinning: From Basic Research to Commercialization; The Royal Society of Chemistry: Glasgow, UK, 2018; pp. 238-260. [CrossRef]

41. Jaworek, A. Micro- and nanoparticle production by electrospraying. Powder Technol. 2007, 176, $18-35$. [CrossRef]

42. Basar, A.O.; Castro, S.; Torres-Giner, S.; Lagaron, J.M.; Turkoglu Sasmazel, H. Novel poly( $\varepsilon$-caprolactone)/gelatin wound dressings prepared by emulsion electrospinning with controlled release capacity of Ketoprofen anti-inflammatory drug. Mater. Sci. Eng. C 2017, 81, 459-468. [CrossRef]

43. Pérez-Masiá, R.; Lagaron, J.M.; Lopez-Rubio, A. Morphology and Stability of Edible Lycopene-Containing Micro- and Nanocapsules Produced Through Electrospraying and Spray Drying. Food Bioprocess Technol. 2015, 8, 459-470. [CrossRef]

44. Prieto, C.; Lagaron, J.M. Nanodroplets of Docosahexaenoic Acid-Enriched Algae Oil Encapsulated within Microparticles of Hydrocolloids by Emulsion Electrospraying Assisted by Pressurized Gas. Nanomaterials 2020, 10, 270. [CrossRef]

45. Faggian, M.; Sut, S.; Perissutti, B.; Baldan, V.; Grabnar, I.; Dall'Acqua, S. Natural Deep Eutectic Solvents (NADES) as a Tool for Bioavailability Improvement: Pharmacokinetics of Rutin Dissolved in Proline/Glycine after Oral Administration in Rats: Possible Application in Nutraceuticals. Molecules 2016, 21, 1531. [CrossRef] [PubMed]

46. Food and Nutrition Board from the Institute of Medicine. Dietary Reference Intakes for Vitamin A, Vitamin K, Arsenic, Boron, Chromium, Copper, Iodine, Iron, Manganese, Molybdenum, Nickel, Silicon, Vanadiumn and Zinc; National Academy Press: Washington, DC, USA, 2001.

47. Lin, Q.; Liang, R.; Williams, P.A.; Zhong, F. Factors affecting the bioaccessibility of $\beta$-carotene in lipid-based microcapsules: Digestive conditions, the composition, structure and physical state of microcapsules. Food Hydrocoll. 2018, 77, 187-203. [CrossRef]

48. Andrade, J.; Pereira, C.; Carlos de Almeida Junior, J.; Carvalho Ramos Viana, C.; De Oliveira Neves, L.; Silva, P.H.; Bell, M.J.; Anjos, V. FTIR-ATR Determination of Protein Content to Evaluate Whey Protein Concentrate Adulteration. LWT 2018, 99, 166-172. [CrossRef]

49. Pereira, R.C.; Carneiro, J.d.D.S.; Assis, O.B.; Borges, S.V. Mechanical and structural characterization of whey protein concentrate/montmorillonite/lycopene films. J. Sci. Food Agric. 2017, 97, 4978-4986. [CrossRef] [PubMed]

50. Karnnet, S.; Potiyaraj, P.; Pimpan, V. Preparation and properties of biodegradable stearic acid-modified gelatin films. Polym. Degrad. Stab. 2005, 90, 106-110. [CrossRef]

51. Upadhyay, N.; Jaiswal, P.; Jha, S.N. Application of attenuated total reflectance Fourier Transform Infrared spectroscopy (ATR-FTIR) in MIR range coupled with chemometrics for detection of pig body fat in pure ghee (heat clarified milk fat). J. Mol. Struct. 2018, 1153, 275-281. [CrossRef]

52. Othman, Z.; Koketsu, M.; Abd Karim, N.; Irwan Zubairi, S.; Hassan, N. Interaction Study of Binary Solvent Systems Ionic Liquid and Deep Eutectic Solvent with Rotenone. Sains Malays. 2018, 47, 1473-1482. [CrossRef]

53. Fernandez, A.; Torres-Giner, S.; Lagaron, J.M. Novel route to stabilization of bioactive antioxidants by encapsulation in electrospun fibers of zein prolamine. Food Hydrocoll. 2009, 23, 1427-1432. [CrossRef]

54. Flaxbart, D. Kirk-Othmer Encyclopedia of Chemical Technology, Fourth Edition, 27-Volume Set Wiley Interscience: New York, 1992-1998. \$7884. ISBN 0-471-52704-1. J. Am. Chem. Soc. 1999, 121, 2339. [CrossRef]

Sample Availability: Samples of the compounds are available from the authors. 